\title{
Internações por condições sensíveis: possibilidade de avaliação na atenção básica
}

\author{
Hospitalizations due to sensitive conditions: the possibility of assessment in primary care
}

Internaciones por condiciones sensibles: posibilidad de evaluación en la atención primaria

Marianna Ferreira ${ }^{1}$, Bruna Moreno Dias ${ }^{2}$, Silvana Martins Mishima ${ }^{3}$

\section{RESUMO}

Condições Sensíveis à Atenção Primária (CSAP) são problemas de saúde atendidos por ações típicas do primeiro nível de atenção cuja evolução, na falta de atenção oportuna e efetiva, pode exigir hospitalização. O presente trabalho trata-se de estudo descritivo, que objetivou analisar a ocorrência de internações por CSAP nos anos de 2000 e 2007, nos residentes de Ribeirão Preto-SP. Nota-se que após implantação da Estratégia Saúde da Família houve queda de 9,6\% nas ocorrências de internações por CSAP. Entretanto, grupos como Doenças Preveníveis por Imunização e Condições Sensíveis, e Anemias apresentaram significativos acréscimos. Esta análise permite inferir que a organização dos serviços de APS no município, embora traga ações de prevenção de doenças e promoção da saúde que parecem contribuir na redução de internações, apresenta-se limitada em seu conjunto, visto que há acréscimos no número de internações em grupos de agravos importantes no contexto da APS e da ação da enfermagem.

Descritores: Enfermagem em Saúde Comunitária; Atenção Primária à Saúde; Utilização; Hospitalização; Avaliação de Serviços de Saúde.

\section{ABSTRACT}

Primary Care Sensitive Conditions (PCSC) are health problems treated using interventions typical of the primary healthcare level, which evolution caused be a lack of timely and effective care, may require hospitalization. This descriptive study was performed with the objective to analyze the occurrence of hospital admissions due to PCSC in the period spanning 2000 to 2007, among inhabitants of Ribeirão Preto - São Paulo. It is observed that after the implementation of the Family Health Strategy, there was a $9.6 \%$ reduction in hospital admissions by PCSC. However, significant increases were observed in groups such as Diseases Preventable by Immunization and Sensitive Conditions, and Anemia. This analysis suggests that despite the fact that public healthcare services in Ribeirão Preto promote interventions that prevent diseases and promote health, which appear to help reduce hospital admissions, there is and overall limited organization of the services, as there has been an increase in the number of admissions in groups with relevant diseases in the context of public healthcare service and nursing care.

Descriptors: Community Health Nursing; Primary Health Care; Utilization; Hospitalization; Health Services Evaluation.

\section{RESUMEN}

Las Condiciones Sensibles a la Atención Primaria (CSAP) son problemas de salud atendidos mediante acciones típicas del primer nivel de atención, cuya evolución, ante falta de atención oportuna, podría exigir hospitalización. Estudio descriptivo, objetivando analizar la ocurrencia de internaciones por CSAP entre 200 y 2007, en residentes de Ribeirão Preto-SP. Es notorio que luego de implantarse la Estrategia Salud de la Familia hubo una disminución de 9,6\% en la ocurrencia de internaciones por CSAP. Entretanto, grupos como Enfermedades Prevenibles por Inmunización y Condiciones Sensibles, y Anemias, presentaron crecimientos significativos. Se infiere que la organización de APS en el municipio, a pesar de incluir acciones preventivas de enfermedades y promoción de la salud, que parecen colaborar reduciendo las internaciones, se muestran limitados en su conjunto, demostrado esto por el incremento de número de internaciones en grupos de padecimientos importantes en el contexto de la APS y de la acción de enfermería.

Descriptores: Enfermería en Salud Comunitaria; Atención Primaria de Salud; Utilización; Hospitalización; Evaluación de Servicios de Salud.

\footnotetext{
${ }^{1}$ Acadêmica do $8^{\circ}$ período do curso de Graduação em em Enfermagem da Escola de Enfermagem de Ribeirão Preto da Universidade de São Paulo (EERP/USP). Ribeirão Preto, SP, Brasil. E-mail: marianna.ferreira@usp.br.

${ }^{2}$ Enfermeira. Ribeirão Preto, SP, Brasil. E-mail: brunamoreno@yahoo.com.br.

${ }^{3}$ Enfermeira, Doutora em Enfermagem. Professora Titular da EERP/USP. Ribeirão Preto, SP, Brasil. E-mail: smishima@eerp.usp.br.
} 


\section{INTRODUÇÃO}

Este estudo faz parte de projeto maior denominado "Condições Sensíveis à Atenção Primária: perfil das internações no município de Ribeirão Preto-SP", em que se objetiva estabelecer uma série histórica destas internações para o município de Ribeirão Preto, São Paulo-Brasil, visando analisar o comportamento das internações por Condições Sensíveis à Atenção Primária (CSAP) neste município e, desta forma, contribuir para organização das ações de saúde e enfermagem no âmbito dos serviços de atenção primária de saúde.

Condições Sensíveis à Atenção Primária (CSAP) são problemas de saúde atendidos por ações típicas do primeiro nível de atenção, cuja evolução, na falta de atenção oportuna e efetiva, pode exigir a hospitalização(1). O conceito de CSAP é relativamente novo, tendo sido criado no final da década de 80 , nos Estados Unidos, por John Billings, e desenvolvido baseado no conceito de mortes evitáveis com o intuito de identificar camadas da população norte-americana sem acesso à atenção ambulatorial bem como conhecer/estudar o impacto financeiro decorrente deste fator.

A partir de então, as internações por CSAP vem sendo amplamente utilizada em diversos outros países. A Espanha, por possuir um sistema nacional de saúde universal, com base na Atenção Primária à Saúde (APS), apresenta aplicação das CSAP um pouco diferente da original, passando a serem utilizadas como indicador de efetividade do nível primário da assistência à saúde(2-5). No Brasil, a aplicação deste conceito ainda é recente, podendo-se notar uma ampliação das publicações nacionais a partir do ano de 2008.

Com o avanço científico nacional nesta temática, aliado à possibilidade de sua utilização como um indicador de acesso e qualidade da atenção, assim como um indicador indireto de efetividade da atenção primária, passa a haver um impulso na necessidade da criação de uma lista de condições sensíveis adaptada à realidade brasileira, e que possibilitasse sua aplicabilidade no contexto nacional $(2,5)$. Assim, a Lista Brasileira de Internações por Condições Sensíveis à Atenção Primária foi criada com o propósito de desenvolver uma ferramenta que contribuísse para a avaliação da atenção básica do país ${ }^{(2,5)}$.

Considerando a estrutura atual do sistema de saúde brasileiro pautado nos atributos e características essenciais da APS, o Sistema Único de Saúde (SUS) volta seus objetivos para a melhoria das condições de saúde da população e minimização das diferenças de acesso aos serviços de saúde dentro dos subgrupos populacionais. Como tentativa de mudança da estrutura da APS brasileira, foi implantado, em 1994, o Programa Saúde da Família, atualmente considerado Estratégia de Saúde da Família (ESF), uma vez que passa a ser uma proposta estruturante do sistema de saúde brasileiro, com forte incremento em vários estados do país ${ }^{(6)}$. Entretanto, o Ministério da Saúde afirma que a consolidação dessa estratégia precisa ser sustentada pela capacidade de produção de resultados positivos nos indicadores de saúde e de qualidade de vida da população assistida.

A utilização de indicadores de saúde permite o estabelecimento de padrões, bem como o acompanhamento de sua evolução ao longo dos anos, que de certa forma facilita a compreensão da realidade social, constituindo-se em ferramentas auxiliadoras do processo de avaliação das ações implantadas. Adotando as internações por CSAP, como um indicador de efetividade, no sentido de avaliar os serviços de saúde no nível primário, pode-se perceber que este fornece subsídios ao planejamento de ações de saúde, permitindo realizar uma avaliação da efetividade dos serviços, programas e políticas. Neste sentido, tem-se que a resolubilidade da APS deve resultar na diminuição das internações hospitalares por um grupo de causas específicas ${ }^{(3)}$, sendo que elevados números de hospitalizações evitáveis podem ser indicativos de problemas relacionados com a rede de atenção básica, independentemente de qual setor apresente falhas ${ }^{(7)}$. Nesta direção, podemos observar que na literatura científica, há uma crescente consistência de que o acesso a serviços ambulatoriais reflete na diminuição de internações por $\operatorname{CSAP}^{(1)}$.

No cenário brasileiro, a reestruturação da APS se dá a partir da configuração do modelo pautado na ESF, fazendo necessária a avaliação da efetividade desta estratégia nos distintos espaços onde esta se encontra instalada. Este tipo de avaliação torna-se importante no nível municipal, uma vez que é de sua responsabilidade monitorar e avaliar a efetividade dos cuidados de saúde ofertados. Sendo assim, a análise das internações por CSAP permite identificar, de modo objetivo e comparável, parcelas da população carentes de APS adequada. Considerando o quadro delineado, o presente estudo apresenta como objetivo geral descrever e analisar a ocorrência de internações por CSAP nos 
residentes do município de Ribeirão Preto-SP nos anos de 2000 e 2007, indicando as variações presentes para os distintos grupos das CSAP.

\section{MATERIAL E MÉTODOS}

Trata-se de estudo exploratório descritivo de corte transversal, visando identificar a situação das internações por CSAP nos anos de 2000 e 2007. Teve como cenário o município de Ribeirão Preto, localizado na Região Nordeste do Estado de São Paulo, com 604.682 habitantes, segundo o último censo populacional( ${ }^{(8)}$. Ribeirão Preto pertence a área de abrangência do Departamento Regional de Saúde XIII (DRS-XIII), sendo este o maior e mais populoso município desta área, constituindo-se pólo assistencial regional, ou seja, referência em ações e serviços de saúde de média e alta complexidade. Ribeirão Preto é composto por cinco distritos de saúde (norte, sul, central, leste e oeste), onde encontram-se distribuídas 21 Unidades Básicas de Saúde (UBS) e cinco Unidades Básicas Distritais de Saúde (UBDS), além de 13 unidades de Saúde da Família. Na assistência hospitalar, o município conta com 15 unidades hospitalares, disponibilizando $71,5 \%$ dos leitos hospitalares existentes para o Sistema Único de Saúde (SUS).

Os dados do estudo são de fontes secundárias, originários de banco de dados do Centro de Processamento de Dados Hospitalares (CPDH) do Hospital das Clínicas de Ribeirão Preto da Faculdade de Medicina de Ribeirão Preto da Universidade de São Paulo (HCFMRP/USP), sendo estes fornecidos em maio de 2010 por meio de solicitação e autorização prévia, seguindo as normas estipuladas pela unidade.

Buscou-se a identificação das internações de usuários com procedência do município de Ribeirão Preto, ocorridas no mesmo município nos anos de 2000 e 2007, sendo analisadas especificamente as internações por CSAP, definidas segundo a Portaria n²21/2008 a qual define a Lista Brasileira de Condições Sensíveis à Atenção Primária ${ }^{(9)}$.

O ano de 2000 foi selecionado como corte inicial, pois indica o perfil das internações por CSAP antes da efetiva implantação da ESF no município de Ribeirão Preto, uma vez que no ano de 2001, se dá efetivamente o início da ESF em Ribeirão Preto. Já o ano de 2007 foi selecionado, por ser o último ano em que o $\mathrm{CPDH}$ do $\mathrm{HC}$ FMRP/USP, apresenta dados consolidados. Para o desenvolvimento do estudo, a investigação teve autorização do HC-FMRP/USP e aprovação do Comitê de Ética em Pesquisa da EERP-USP segundo protocolo n¹137/2010. Utilizou-se para a análise dos dados, estatística descritiva com a apresentação numérica e percentual dos agravos, assim como o percentual de sua variação entre os dois anos.

\section{RESULTADOS}

Na Tabela 1, apresenta-se o número de internações por CSAP para os anos de 2000 e 2007, segundo os diferentes grupos que compõem a Lista Brasileira de CSAP. Observa-se um total de internações de pessoas residentes no município de Ribeirão Preto por CSAP de 9.531 casos para o ano 2000 e 8.616 casos ocorridos no ano de 2007, podendo-se verificar uma diminuição de 915 casos. Este total representa um decréscimo de $9,6 \%$ no total de ocorrências, em função da queda na ocorrência dos agravos em diferentes grupos de agravos. 
Tabela 1: Distribuição numérica dos Grupos de CSAP para os anos de 2000 e 2007 em residentes do município de Ribeirão Preto. Ribeirão Preto, SP, 2010.

\begin{tabular}{|c|c|c|c|c|}
\hline GRUPO & Condições Sensíveis & 2000 & 2007 & \% de variação \\
\hline 1 & Doenças preveníveis por imunização e CSAP & 82 & 119 & 45,1 \\
\hline 2 & Gastroenterites infecciosas e complicações & 1286 & 670 & $-47,9$ \\
\hline 3 & Anemia & 12 & 18 & 50 \\
\hline 4 & Deficiências nutricionais & 54 & 45 & $-16,6$ \\
\hline 5 & Infecções de ouvido, nariz e garganta & 203 & 164 & $-19,2$ \\
\hline 6 & Pneumonias bacterianas & 311 & 299 & $-3,8$ \\
\hline 7 & Asma & 301 & 348 & 15,6 \\
\hline 8 & Doenças pulmonares & 1093 & 775 & -29 \\
\hline 9 & Hipertensão & 628 & 694 & 10,5 \\
\hline 10 & Angina & 945 & 920 & $-2,6$ \\
\hline 11 & Insuficiência cardíaca & 920 & 873 & $-5,1$ \\
\hline 12 & Doenças cerebrovasculares & 1021 & 1139 & 11,5 \\
\hline 13 & Diabetes mellitus & 520 & 400 & -23 \\
\hline 14 & Epilepsias & 278 & 230 & $-17,2$ \\
\hline 15 & Infecção no rim e trato urinário & 538 & 700 & 30,1 \\
\hline 16 & Infecção da pele e tecido subcutâneo & 373 & 433 & 16 \\
\hline 17 & Doença inflamatória órgãos pélvicos femininos & 187 & 198 & 5,8 \\
\hline 18 & Úlcera gastrointestinal & 630 & 464 & $-26,3$ \\
\hline \multirow[t]{2}{*}{19} & Doenças relacionadas ao pré-natal e parto & 149 & 127 & $-14,7$ \\
\hline & TOTAL DE SENSÍVEIS & 9.531 & 8.616 & $-9,6$ \\
\hline
\end{tabular}

O Grupo 1 - Doenças Preveníveis por Imunização e Condições Sensíveis e o Grupo 3 - Anemia são os dois grupos com maior crescimento entre os dois anos estudados. Para o Grupo 1 foi verificado um total de 82 internações para o ano de 2000 e 119 internações no ano de 2007 , com um aumento de $45,1 \%$ no conjunto das internações neste grupo. Já o Grupo 3, é o que apresenta maior crescimento no período (50\%). Em relação à maior queda é verificada para o Grupo 2 - Gastroenterites infecciosas e complicações (47,9\%).

A Tabela 2 apresenta o número de internações por CSAP pertencentes ao Grupo 1, para os anos de 2000 e 2007, segundo seus subgrupos. 
Tabela 2: Distribuição numérica dos subgrupos de CSAP pertencentes ao Grupo 1 da Lista Brasileira de CSAP para os anos de 2000 e 2007. Ribeirão Preto, SP, 2010.

\begin{tabular}{cccc}
\hline Grupo 1 - Doenças preveníveis por imunização e CSAP & $\mathbf{2 0 0 0}$ & $\mathbf{2 0 0 7}$ & \% de variação \\
\hline Coqueluche & 2 & 10 & 400 \\
Difteria & 0 & 0 & - \\
Tétano & 1 & 1 & - \\
Parotidite & 0 & 5 & 500 \\
Rubéola & 0 & 1 & 100 \\
Sarampo & 0 & 0 & - \\
Febre amarela & 1 & 0 & -100 \\
Hepatite & 1 & - & -50 \\
Meningite haemophilus & 2 & 2 & -100 \\
Meningite tuberculosa & 2 & 1 & - \\
Tuberculose miliar & 1 & 0 & 47,8 \\
Tuberculose pulmonar & 2 & 2 & 100 \\
Outras tuberculoses & 46 & 68 & $-33,3$ \\
Febre reumática & 5 & 10 & -20 \\
Sífilis & 6 & 4 & 900 \\
Malária & 5 & 4 & $-87,5$ \\
\hline Ascaridíase & 1 & 10 & $\mathbf{5 , 1}$ \\
\hline
\end{tabular}

Fonte: $\mathrm{CDPH}, 2010$.

Para a ocorrência de Coqueluche, embora haja controle por imunização regular na rede municipal e no estado de São Paulo, prevista no Programa Nacional de Imunização, houve aumento de $400 \%$ do ano de 2000 para o ano de 2007. Ainda, chama atenção o aumento expressivo de $900 \%$ dos casos de Malária, entre 2000 e 2007. Parotidite não apresentou nenhum caso para o ano 2000, entretanto apresentou cinco casos em 2007, representando $500 \%$ de acréscimo. A Tuberculose, considerando seus diferentes subgrupos, apresentou um aumento de $147,8 \%$ dos casos, no período estudado. O subgrupo Ascaridíase foi o que apresentou o maior decréscimo $87,5 \%$ de casos.

Cabe destacar que embora altos, os percentuais identificados, quando observada a ocorrência dos agravos neste Grupo 1, em números absolutos, estes apresentam-se pequenos, ou seja, há variação de um caso de 2000 para 2007 por exemplo para: Rubéola, Febre amarela, Meningite haemophilus, Meningite tuberculosa.

O Grupo 2 - Gastroenterites infecciosas e complicações, composto por dois subgrupos (desidratação e gastroenterites) apresenta decréscimo de 47,9\% dos casos, ressaltando que esta diminuição ocorre em todos os subgrupos. O Grupo 3, denominado Anemia, contém apenas um subgrupo, Anemia por deficiência de ferro, sendo 12 casos para o ano de 2000 e 18 casos em 2007, evidenciando aumento de $50 \%$ dos casos, como já apontado, sendo o agravo com maior crescimento no período.

Deficiências Nutricionais estão categorizadas como sendo Grupo 4, sendo este dividido em dois subgrupos: 1) Kwashiokor e outras formas de desnutrição proteico calórica; 2) outras deficiências nutricionais. Embora este grupo apresente decréscimo de $16,6 \%$ dos casos em sua totalidade, o subgrupo outras deficiências nutricionais sofreu aumento de $12,5 \%$ dos casos.

Na Tabela 3 estão apresentados os números de internações por CSAP para os anos de 2000 e 2007, segundo os subgrupos pertencentes ao Grupo 5 - Infecções de ouvido, nariz e garganta, ao Grupo 6 - Pneumonias Bacterianas e Grupo 8 - Doenças Pulmonares. Observa-se que houve diminuição de $19,2 \%$ dos casos de internações referentes ao Grupo 5, embora a maioria dos subgrupos apresente aumento nos números de casos de internação do ano 2000 para o de 2007, sendo que a maioria dos subgrupos apresentou aumento expressivo, tendo destaque Rinite, Nasofaringite e Faringite crônica, e Nasofaringite aguda. 
Tabela 3: Distribuição numérica dos subgrupos de CSAP pertencentes ao Grupo 5, Grupo 6 e Grupo 8 da Lista Brasileira de CSAP para os anos de 2000 e 2007. Ribeirão Preto, SP, 2010

\begin{tabular}{|c|c|c|c|}
\hline Grupo 5 - Infecções de ouvido, nariz e garganta & 2000 & 2007 & \% de variação \\
\hline Otite media supurativa & 117 & 63 & $-46,1$ \\
\hline Nasofaringite aguda & 2 & 4 & 100 \\
\hline Sinusite aguda & 12 & 18 & 50 \\
\hline Faringite aguda & 4 & 6 & 50 \\
\hline Amigdalite aguda & 31 & 41 & 32,2 \\
\hline Infecção Aguda de Vias Aéreas Superiores & 36 & 29 & $-19,4$ \\
\hline Rinite, Nasofaringe e Faringite Crônica & 1 & 3 & 200 \\
\hline \multicolumn{4}{|l|}{ Grupo 6 - Pneumonias bacterianas } \\
\hline Pneumonia pneumocócica & 7 & 32 & 357,1 \\
\hline Pneumonia por Haemophilus influenzae & 0 & 0 & - \\
\hline Pneumonia por Streptococus & 0 & 0 & - \\
\hline Pneumonia bacteriana NE & 109 & 228 & 109,1 \\
\hline Pneumonia lobar NE & 195 & 39 & -80 \\
\hline \multicolumn{4}{|l|}{ Grupo 8 - Doenças Pulmonares } \\
\hline Bronquite aguda & 266 & 261 & $-1,8$ \\
\hline Bronquite NE aguda ou crônica & 41 & 16 & $-60,9$ \\
\hline Bronquite crônica simples & 0 & 0 & \\
\hline Bronquite crônica NE & 38 & 1 & $-97,3$ \\
\hline Enfisema & 66 & 8 & $-87,8$ \\
\hline Bronquectasia & 54 & 26 & $-51,8$ \\
\hline Outras DPOC & 628 & 463 & $-26,2$ \\
\hline
\end{tabular}

Para o Grupo 6, observa-se decréscimo de 3,8\% dos casos de internações, decorrente da queda do número de casos de Pneumonia Lobar considerando o período entre 2000 e 2007, contudo, considerando os subgrupos das Pneumonias Pneumocócica e Bacteriana NE, estes apresentam crescimento acima de $100 \%$. Para o Grupo 7 Asma, e consequentemente, para seu único subgrupo, observa-se aumento de $15,6 \%$ dos casos de internações para 2007 em relação a 2000.

Já em relação às internações por Doenças Pulmonares (Grupo 8) nota-se decréscimo de $29 \%$ dos casos relacionados, ressaltando a significância dos subgrupos Bronquite crônica não específica, Enfisema e Bronquite não específica aguda ou crônica, dentre os subgrupos que apresentam maior queda no número de casos.

Em 2000, para o Grupo 9 - Hipertensão, ocorreram 628 internações, no entanto, para o ano de 2007 houve aumento de $10,5 \%$ dos casos, estando estes divididos nos subgrupos Hipertensão essencial e Doença cardíaca hipertensiva. Com apenas um subgrupo (Angina Pectoris) o Grupo 10 - Angina apresentou um total de 945 internações no ano de 2000, já para 2007, apresentou 920 casos de hospitalização, totalizando um decréscimo de $2,6 \%$ das ocorrências de internações. Também apresentou decréscimo o Grupo 11 - Insuficiência Cardíaca, sendo este de 5,1\%, no entanto cabe ressaltar o aumento expressivo ocorrido no subgrupo Edema Agudo de Pulmão de 51,5\%, notando decréscimo $(11,7 \%)$ apenas no subgrupo Insuficiência cardíaca.

Рага o Grupo 12 - Doenças cerebrovasculares, com apenas um subgrupo, nota-se acréscimo de $11,5 \%$ dos casos ocorridos no ano de 2007 em relação ao ano de 2000. Já o Grupo 13 - Diabetes Mellitus, apresentou decréscimo de $23 \%$ dos casos em relação aos anos estudados, cabendo ressaltar que todos os seus subgrupos também apresentaram decréscimo no número de internações. Em relação ao Grupo 14 Epilepsias -nota-se também importante decréscimo nos casos de internações, sendo este de $17,2 \%$.

Na Tabela 4 estão representadas as internações, segundo o Grupo 15 - Infecção no Rim e Trato Urinário, Grupo 16 - Infecção da pele e tecido subcutâneo e Grupo 17 - Doença inflamatória dos órgãos pélvicos feminino, e seus respectivos subgrupos para os anos de 2000 e 2007 e a variação percentual dos casos. 
Tabela 4: Distribuição numérica dos subgrupos de CSAP pertencentes ao Grupo 15, Grupo 16 e Grupo 17 da Lista Brasileira de CSAP para os anos de 2000 e 2007. Ribeirão Preto, SP, 2010.

\begin{tabular}{lccc}
\hline Grupo 15 - Infecção no rim e trato urinário & $\mathbf{2 0 0 0}$ & $\mathbf{2 0 0 7}$ & $\mathbf{\%}$ de variação \\
\hline Nefrite túbulo intersticial aguda & 107 & 120 & 12,1 \\
Nefrite túbulo intersticial crônica & 4 & 3 & -25 \\
Nefrite túbulo intersticial NE aguda & 108 & 123 & 13,8 \\
Cistite & 14 & 16 & 14,2 \\
Uretrite & 0 & 0 & - \\
Infecções do trato urinário & 305 & 438 & 43,6 \\
\hline Grupo 16 - Infecção da pele e tecido subcutâneo & & \\
\hline Erisipela & 93 & 97 & 4,3 \\
Impetigo & 34 & 33 & $-2,9$ \\
Abscesso cutâneo & 160 & 165 & 3,1 \\
Celulite & 72 & 111 & 84,7 \\
Linfadenite aguda & 3 & 7 & 133,3 \\
Outras infecções locais de pele & 11 & 20 & 81,8 \\
\hline Grupo 17 - Doença inflamatória dos órgãos pélvicos feminino & \multicolumn{3}{c}{} \\
\hline Salpingite e ooforite & 60 & 40 & $-33,3$ \\
Doença inflamatória do útero exceto o colo & 11 & 9 & $-18,1$ \\
Doença inflamatória do colo de útero & 1 & 1 & - \\
Outras doenças inflamatórias pélvicas femininas & 60 & 57 & -5 \\
Doença da glândula de Bartholin & 47 & 79 & 68 \\
Outras afecções inflamatórias da vagina e da vulva & 8 & 12 & 50
\end{tabular}
Fonte: $\mathrm{CDPH}, 2010$.

Nota-se aumento de $30,1 \%$ nos casos para o Grupo 15. Para o Grupo 16 - Infecção da pele e tecido subcutâneo, houve acréscimo de $16 \%$ dos casos para o ano de 2007 em relação ao ano de 2000, sendo que o subgrupo da Linfadenite aguda foi o que apresentou aumento mais significativo, seguido pelos subgrupos Celulite e outras infecções locais de pele, respectivamente. É importante ressaltar que apenas um único subgrupo apresentou decréscimo, o Impetigo.

Para o Grupo 17 - Doença Inflamatória dos órgãos pélvicos feminino houve acréscimo de internações em relação aos anos analisados na ordem de 5,8\%. Embora a maioria dos subgrupos tenha apresentado decréscimo, o aumento recorrente de dois subgrupos torna-se expressivo, alterando o perfil da variação dos casos deste grupo.

Рara o Grupo 18 - Úlcera Gastrointestinal, verificouse um total de 630 casos em 2000, e 464 casos de internações ocorridos em 2007, caracterizando assim um decréscimo de $26,3 \%$ para este grupo e seu único subgrupo. Quanto ao último grupo da Lista de Condições Sensíveis (Grupo 19 - Doenças relacionadas ao pré-natal e parto) observa-se um decréscimo de $14,7 \%$ dos casos em relação aos anos analisados, sendo que um de seus três subgrupos não apresentou variação no número de casos.
Outro fato observado é que as internações por CSAP, para ambos os anos estudados, são mais prevalentes para o sexo feminino, 4.927 para o ano 2000 e 4.633 no ano de 2007, do que o sexo masculino, com ocorrência de 4.604 internações no ano 2000 e 3.983 em 2007.

\section{DISCUSSÃO}

Nos dados apresentados, de modo geral, pode-se observar um decréscimo da frequência de internações por CSAP para os anos de 2000 e 2007, no entanto, alguns grupos, como abordado anteriormente, sofreram significante acréscimo nos casos de internações, podendo citar o Grupo 3 - Anemia, Grupo 1 - Doenças preveníveis por imunização e CSAP, Grupo 15 - Infecção no rim e trato urinário, dentre outros.

Entretanto, para o presente estudo destaca-se a necessidade de análise sobre o Grupo 1, uma vez que este grupo engloba agravos à saúde de efeitos significativos em âmbito nacional e mundial, e ainda refere-se à algumas doenças imunopreviníveis, para as quais se apresentam ações de controle e prevenção previstas no âmbito público, como rege o Programa Nacional de Imunização (PNI), sendo a vacinação um recurso preventivo com alta eficácia, sob responsabilidade da enfermagem tanto no que diz respeito à questão operacional nas salas de vacina, como no monitoramento das distintas etapas deste processo. 
Assim, sabe-se que a vacinação, visando a proteção dos grupos, é de extrema importância para a Enfermagem, pois em todas as etapas pode-se destacar a equipe de enfermagem em atuação, com destaque para a figura do enfermeiro(10). Portanto, o principal objetivo é fornecer conhecimentos sobre dados que possam contribuir com as ações de enfermagem e de saúde no âmbito da APS, buscando compreender a importância das ações realizadas em nível primário de atenção à saúde e seus reflexos para as demais instituições de saúde.

Em relação à malária, embora a maioria dos casos no Brasil estejam concentrados na região Norte do país, sua ocorrência é de extensão nacional, o que pode justificar as internações na região de Ribeirão Preto, principalmente considerando a existência de casos importados, em função da mobilidade dos grupos populacionais, tendo em vista que a cidade e a região apresentam grande importância do ponto de vista do trânsito de mercadorias e pessoas. No presente estudo, observa-se significativo acréscimo no subgrupo Malária (900\%) em relação aos anos estudados.

Dados existentes para o Brasil apontam que, após a implantação de diversas políticas públicas que visavam à erradicação da malária, houve significativa redução nos casos da doença. No entanto, observa-se um aumento no número de casos a partir de 2003, na região amazônica, sendo este associado com a intensa e desordenada ocupação das periferias das grandes cidades da região, além do desmatamento para extração de madeira e criação de gado(11).

Em relação aos anos de 2000 e 2007, o Brasil apresentou declínio de $25,5 \%$ na ocorrência de casos de malária, no entanto não foram localizados dados que confirmassem o declínio nos casos de internações decorrentes a este agravo. Em 2007, no estado de São Paulo foram registrados 237 casos confirmados de malária, sendo que 3,8\% foram ocorridos em moradores de Ribeirão Preto, e todos os casos necessitaram de internação hospitalar. Destes 237 casos notificados, 210 (89\%) residiam no próprio estado de São Paulo, sendo a maior parte dos casos de origem importado, 42 importados de outros países e 140 de outros estados brasileiros, principalmente daqueles localizados na região amazônica; e 46 casos (19,4\%) eram autóctones do Estado de São Paulo(12). Estudo recente afirma que a autoctonia da malária no estado de São Paulo vem apresentando aumento principalmente em duas grandes regiões do estado, sendo elas: a região da Serra do Mar (ecossistema com presença de Mata Atlântica) e a região Oeste do estado, principalmente próximo as áreas de bacias hidrográficas, região na qual o município de Ribeirão Preto está situado(13).

Parotidite, também apresentou acréscimo de 500\% na ocorrência de internações hospitalares do ano de 2007 em relação a 2000 em Ribeirão Preto. A Parotidite infecciosa costuma apresentar-se sob a forma de surtos, acometendo principalmente crianças, entretanto estimase que, na ausência de imunização, $85 \%$ dos adultos poderão apresentar a doença, sendo esta mais severa em adultos(11).

Não diferindo do município de Ribeirão Preto, o estado de São Paulo, em 2007, apresentou um importante acréscimo na ocorrência de surtos em relação aos anos anteriores, no entanto, não foi possível comparar com o ano de 2000 pela ausência do dado referente a este ano. Ocorreram 768 surtos no estado de São Paulo, totalizando 3.404 casos de Parotidite ${ }^{(12)}$. Ribeirão Preto, no ano de 2007 apresentou 627 casos notificados, grande parte deles ocorridos em um surto, principalmente entre escolares. A este fato foi atribuída a ocorrência de uma "Falha vacinal" devido à aplicação de uma única dose da vacina tríplice viral até 2004 , sendo que esta foi introduzida na rede pública de saúde em $1992^{(14)}$. Portanto, quem nasceu antes ou nunca foi vacinado ou recebeu apenas uma dose, não teria "garantia" de proteção contra o vírus causador da parotidite, caracterizando um surto com acometimento principalmente de adolescentes ${ }^{(15)}$.

Outro subgrupo que apresentou forte acréscimo nos números de internações foi o da Coqueluche. Esta doença foi a principal causa de morbimortalidade infantil em todo o mundo até a introdução da vacina específica na década de 1940, o que possibilitou uma brusca redução na ocorrência mundial da Coqueluche(11). Entretanto, desde a década de 1980, a Coqueluche tornou-se, em muitos países, um importante problema de saúde pública, pois o que se observa é o ressurgimento da doença em locais de alta incidência da cobertura vacinal, tal fato pode estar relacionado com a provável perda gradual da imunidade adquirida e com a adaptação da população bacteriana à imunidade induzida pela vacina ${ }^{(16)}$.

Embora a literatura apresente dados em decréscimo para os casos de Coqueluche, os resultados do presente estudo apontam características diferenciadas para Ribeirão 
Preto e para o estado de São Paulo nos anos analisados. Nota-se que, em Ribeirão Preto, para o ano de 2007, em relação a 2000 , houve aumento de oito casos (400\%) de internações por Coqueluche. Comparando os resultados encontrados com as ocorrências de casos da Coqueluche para o estado de São Paulo, observa-se aumento de 143,7\% dos casos para os anos considerados ${ }^{(12)}$.

É importante salientar que a Coqueluche pode ser prevenida por imunização e que altos índices de cobertura vacinal acarretam em baixos números de casos de Coqueluche, assim pode-se relacionar os dados citados com a cobertura vacinal de tetravalente (instituída em substituição da vacina tríplice bacteriana DTP). Observa-se para o estado de São Paulo que um total de $96,9 \%$ da população foi vacinada no ano de 2007. Para o ano de 2003, a cobertura vacinal foi de $98,7 \%$, no entanto, esse dado não está contabilizado para o ano de $2000^{(12)}$. Para Ribeirão Preto, também ocorreu decréscimo da cobertura vacinal da população em relação a 2007, com relação aos anos anteriores, sendo de $97,2 \%$ a cobertura populacional pela vacina tríplice bacteriana (DTP) em 2000 e de 95,9\% da população vacinada com a vacina tetravalente em 2007, indicando uma provável relação com o aumento no número de internações por Coqueluche para os anos analisados $^{(14)}$.

A Tuberculose (TB) permanece como um dos maiores problemas de saúde pública mundial, acometendo grande parte da população. Por tratar-se de uma doença de ocorrência mundial, observa-se que em países desenvolvidos os índices de morbidade e mortalidade possuem tendência decrescente. A prevalência observada da TB é maior em áreas de grande concentração populacional e precárias condições socioeconômicas e sanitárias ${ }^{(11)}$.

Atualmente, pode-se observar que parte significativa dos casos de TB está associada a infecções oportunistas, coinfecções, principalmente em pacientes com sorologia positiva para HIV. Nas áreas com elevada prevalência de infecção pelo HIV, vem ocorrendo estabilização, ou aumento do número de casos e óbitos por tuberculose ${ }^{(11)}$. Embora o país apresente grande parte da população infectada por TB, é indicado para tratamento o acompanhamento ambulatorial, que se demonstra eficaz para a maioria dos casos de cura ${ }^{(11)}$.

Em Ribeirão Preto de 2000 para 2007, nota-se um importante acréscimo de $100 \%$ nas internações por TB extra-pulmonar e de $47,8 \%$ nos casos de TB pulmonar, no entanto estes dados diferem tanto na situação do estado de São Paulo como também do país. Internações por TB pulmonar apresentam um decréscimo de $20 \%$ no país e de $54 \%$ no estado de São Paulo, enquanto que internações por outros tipos de TB também apresentam decréscimo, sendo de 25,2\% no Brasil e de 21,4\% para o estado de São Paulo(17). Tal acontecimento pode estar relacionado com falhas no processo de notificações da doença, ou ainda, a subnotificações tanto para o estado quanto para o país, ou mesmo a dificuldade de acompanhamento dos usuários no âmbito do município, podendo com isto indicar problemas na atenção ofertada aos portadores de TB pela rede de atenção local.

A hospitalização é indicada para os casos graves, que apresentam complicações da própria doença, em casos de retratamento ou ainda, por motivos sociais em que a probabilidade de abandono é alta ${ }^{(11)}$. Dentro dos subgrupos da TB destacam-se as internações por TB pulmonar que representam um grande desafio para a saúde pública.

A Meningite tuberculosa é uma das formas graves de TB, pois apesar de não ser uma forma contagiosa, pode ser letal ou causar sequelas neurológicas graves ${ }^{(18)}$. A Meningite tuberculosa não sofre variações sazonais e sua distribuição não é igual em todos os continentes. A doença guarda íntima relação com as características socioeconômicas, principalmente, naqueles países onde a população está sujeita à desnutrição e às condições precárias de habitação. E ainda, indivíduos HIV positivos também têm um maior risco de adoecimento, assim como os outros tipos de $\mathrm{TB}^{(11)}$.

A incidência de Meningite tuberculosa é indicador epidemiológico importante de uma região, pois guarda estreita correlação com a incidência de casos bacilíferos na população adulta, além de indicar baixas coberturas vacinais da vacina contra Tuberculose (Bacilo de Calmette-Guérin - BCG), e ainda apresenta altas taxas de letalidade e de evolução para sequelas em relação a outros tipos de Meningite, aumentando ainda mais os custos relacionados ao tratamento e internações hospitalares ${ }^{(18)}$. Cabe ressaltar que em Ribeirão Preto, para os anos analisados, observa-se decréscimo de $100 \%$ no número de internações, valendo a pena indicar que este percentual, embora alto, se refere a diminuição de um caso em número absoluto. 
A principal forma de prevenção é a detecção e o tratamento precoce das diferentes formas de TB, evitandose, principalmente, que a doença seja transmitida a outras pessoas. Outra medida importante de prevenção é a disponibilidade da vacina BCG no calendário básico de vacinação da criança, que previne as formas graves de

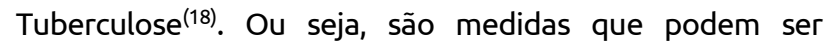
realizadas a nível primário de atenção, evitando assim casos de hospitalizações devido aos agravos da TB.

Nota-se que em relação às internações decorrentes de Febre Amarela, houve decréscimo no município de Ribeirão Preto, assim como da ocorrência da doença no país como um todo. Embora a Febre Amarela apresente dois ciclos epidemiológicos (febre amarela silvestre e urbana), no Brasil, a partir de 1942 há registro apenas de uma de suas apresentações, sendo esta do tipo silvestre ${ }^{(11)}$. Nacionalmente, houve redução de aproximadamente $93 \%$ dos casos de Febre Amarela do ano de 2000 para o ano de 2007. Para o estado de São Paulo, em relação ao mesmo período houve redução de $100 \%$ dos casos, assim como no município de Ribeirão Preto ${ }^{(12)}$.

Nos surtos ocorridos no Brasil, no período de 2000 a 2008, observou-se uma expansão da circulação viral no sentido leste e sul do país, quando comparado com surtos ocorridos nos anos anteriores, onde havia predomínio dos estados da região Norte. Esse caráter dinâmico da epidemiologia da doença tem exigido avaliações periódicas das áreas de risco, assim favorecendo as estratégias para as medidas de prevenção e controle da doença ${ }^{(11)}$. Com isso, em 2003, o Ministério da Saúde, com o objetivo de aumentar a sensibilidade do sistema de vigilância da Febre Amarela, implantou a vigilância de epizootias a partir da notificação de morte de macacos, permitindo a detecção oportuna da circulação do vírus, antes mesmo da ocorrência em humanos(12).

Também apresentou importante decréscimo no número de hospitalizações o subgrupo Ascaridíase, em relação ao período estudado, sendo este de $87,5 \%$. A Ascaridíase possui distribuição mundial, estando presente em lugares de clima tropical e subtropical; possui maior prevalência em áreas rurais e está associada principalmente a condições econômicas e sanitárias precárias ${ }^{(12)}$. Certamente, medidas de saneamento e de educação sanitária para a população, foram responsáveis pelo declínio de sua incidência nas cidades em todo o mundo, podendo haver forte influência dos serviços de saúde em relação a estas precauções ${ }^{(19)}$.

No caso do município de Ribeirão Preto, os dados gerais sobre o saneamento são próximos a $100 \%$ de cobertura para a população em geral, sendo que os percentuais de atendimento da população para a rede de saneamento básico mostram-se sistematicamente superiores aos observados para o estado de São Paulo e outras cidades do interior do estado(20); os registros municipais indicam $99,09 \%$ da população atendida pela rede de abastecimento de água, 97,15\% de coleta de lixo e apenas $5 \%$ da população ainda não atendida pela rede de esgoto(20). Este conjunto de dados sobre a situação presente no município pode reiterar a indicação da literatura acerca do papel decisivo dos serviços de saúde, e das ações de prevenção e promoção por eles desenvolvidas.

Embora a Infecção intestinal em humanos, em geral, seja assintomática ou pouco sintomática, a Ascaridíase pode ser responsável por diversos agravos que podem levar o indivíduo infectado a necessitar de hospitalização. Em infecções maciças - Ascaris lumbricoides pode causar deficiências nutricionais importantes, Pneumonite, Obstrução intestinal e dos ductos pancreático e biliar, e consequentemente algumas vezes pode levar o indivíduo a óbito ${ }^{(12)}$.

Estima-se que de 600 mil a um bilhão de pessoas no mundo, estejam infectadas por Ascaris lumbricoides e que 20 mil pessoas morram anualmente devido a este helminto(19). No entanto, no Brasil, não há dados sistemáticos sobre sua prevalência. Estudos sobre a temática traz relação da prevalência do verme associada à baixa renda familiar, falta de escolaridade e precárias condições de vida ${ }^{(19)}$.

\section{CONCLUSÕES}

Nota-se que após a implantação da Estratégia Saúde da Família, houve decréscimo de 9,6\% no total de ocorrências de internações, em função da queda no número de casos dos agravos em diferentes grupos da Lista Brasileira de Condições Sensíveis.

No entanto, grupos importantes de atuação de nível primário e consequentemente, ligados diretamente a ações de produção de cuidado em saúde pela equipe de enfermagem, apresentaram maiores acréscimos, como o Grupo 1 - Doenças Preveníveis por Imunização e Condições Sensíveis, com um aumento de $45,1 \%$ no 
conjunto das internações. Ainda, o maior aumento na ocorrência de casos foi para o Grupo 3 - Anemias, com crescimento no período de 50\%. Quanto à maior queda, esta foi verificada para o Grupo 2 - Gastroenterites Infecciosas e Complicações.

A análise da situação dos agravos para os dois anos, no cenário de estudo, permite traçar uma linha de base para estudos posteriores, que permitam o monitoramento das CSAP como indicador de acesso aos serviços e da situação de saúde, possibilitando a organização de ações específicas de

\section{REFERÊNCIAS}

1. Nedel FB, Facchini LA, Martín-Mateo M, Navarro A. Características da atenção básica associadas ao risco de internar por condições sensíveis à atenção primária: revisão sistemática da literatura. Epidemiol. Serv. Saude [Internet]. 2010 [cited 2012 dec 31];19(1):6175. Available from: http://dx.doi.org/10.5123/S167949742010000100008.

2. Dourado I, Berenice V. Entrevista. Revista Brasileira Saúde da Família [Internet]. 2008 [cited $2012 \mathrm{dec} 31$ ];IX(18):6-8. Available from: http://189.28.128.100/dab/docs/publicacoes/revistas/revista_saude familia18.pdf.

3. Nedel FB, Facchini LA, Martín-Mateo M, Vieira LAS, Thume E. Programa Saúde da Família e condições sensíveis à atenção primária, Bagé (RS). Rev Saude Publica [Internet]. 2008 [cited 2012 dec 31];42(6):1041-52. Available from: http://dx.doi.org/10.1590/S0034-89102008000600010.

4. Caminal Homar J, Casanova Matutano C. La evolucion de la atención primaria y las hospitalizaciones por ambulatory care sensitive condictions. Marco conceptual. Aten Primaria.

2003;31(1):61-5.

5. Alfradique ME, Bonolo PF, Dourado I, Lima-Costa MF, Macinko J, Mendonça CS et al. Internações por condições sensíveis à atenção primária: a construção da lista brasileira como ferramenta para medir o desempenho do sistema de saúde (Projeto ICSAP - Brasil). Cad Saude Publica [Internet]. 2009 [cited 2012 dec 31];25(6):133749. Available from: http://dx.doi.org/10.1590/S0102311X2009000600016.

6. Gaioso VP, Mishima SM. User satisfaction from the perspective of acceptability in the family health scenario. Texto Contexto Enferm [Internet]. 2007 [cited $2012 \mathrm{dec} 31$ ]; 16(4):617-625. Available from: http://dx.doi.org/10.1590/S0104-07072007000400005.

7. Fernandes VBL, Caldeira AP, Faria AA, Rodrigues Neto JF. Hospitalizations sensitive to primary care as an evaluation indicator for the Family Health Strategy. Rev Saude Publica [Internet]. 2009 [cited 2012 dec 31];43(6):928-36. Available from: http://dx.doi.org/10.1590/S0034-89102009005000080.

8. Instituto Brasileiro de Geografia e Estatística [Internet]. Brasília: Ministério do Planejamento, Orçamento e gestão (BR) [cited 2012 dec 31]. Censo 2010. Available from: http://www.censo2010.ibge.gov.br/.

9. Portaria n.221 de 17 de abril 2008. Define a Lista Brasileira de Internações por Condições Sensíveis da Atenção Básica. Diário Oficial da União (Brasília). 2008 Abr 18.

10. Oliveira VG, Pedrosa KKA, Monteiro Al, Santos ADB. Vacinação: o fazer da enfermagem e o saber das mães e/ou cuidadores. Rev. Rene [Internet]. 2010 [cited $2012 \mathrm{dec} 31$ ];11(spe):133-41. Available from: http://www.revistarene.ufc.br/revista/index.php/revista/article/view/ 478.

11. Secretaria de Vigilância em Saúde, Ministério da Saúde. Guia de vigilância epidemiológica. 7th ed. Brasília (Brasil): Ministério da Saúde; 2009. 816 p.

12. Centro de Vigilância Epidemiológica "Prof. Alexandre Vranjac" [Internet]. São Paulo: Secretária da Saúde de São Paulo (BR) [cited 2011 jul 17]. Centro de Vigilância Epidemiológica - CVE/SES-SP. Available from: http://www.cve.saude.sp.gov.br/. prevenção e promoção a serem desencadeadas nos serviços de APS.

Ainda, pode-se inferir que a organização dos serviços de saúde da APS, na perspectiva da ESF no município, embora traga ações de prevenção de doenças e promoção da saúde que parecem contribuir para a redução da ocorrência de determinados agravos, esta ainda mostra-se com limitação, visto que há acréscimos no número de casos em grupos de agravos importantes no contexto da APS, como doenças preveníveis por vacinação.

13. Couto RD, Latorre MRDO, Santi SMD, Natal D. Malária autóctone notificada no Estado de São Paulo: aspectos clínicos e epidemiológicos de 1980 a 2007. Rev Soc Bras Med Trop [Internet]. 2010 [cited 2012 dec 31];43(1):52-8. Available from: http://dx.doi.org/10.1590/S0037-86822010000100012. 14. Núcleo Hospitalar de Epidemiologia HCRP-FMRP-USP (BR). Informativo Epidemiológico de Ribeirão Preto [Internet]. 2007 [cited 2012 dec 30];III(33). Available from:

http://www.fmrp.usp.br/nhe/download/informativo ierp 33.pdf.

15. Agência Nacional de Vigilância Sanitária [Internet]. Brasília: Ministério da Saúde (BR) [cited 2012 dec 31]. Lista de Adversidade em Saúde: Caxumba SP (Ribeirão Preto). Available from:

http://lisas.anvisa.gov.br/site/mensagem.php?id=2394.

16. Trevizan S, Coutinho SED. Perfil epidemiológico da coqueluche no Rio Grande do Sul, Brasil: estudo da correlação entre incidência e cobertura vacinal. Cad Saude Publica [Internet]. 2008 [cited 2012 dec 31];24(1):93-102. http://dx.doi.org/10.1590/S0102$311 \times 2008000100009$.

17. DATASUS [Internet]. Brasília: Ministério da Saúde (BR) [cited 2012 dec 31]. Informações de Saúde (TABNET). Assistência à Saúde. Available from:

http://www2.datasus.gov.br/DATASUS/index.php?area=0202. 18. Sociedade Brasileira de Infectologia [Internet]. São Paulo: Sociedade Brasileira de Infectologia (BR) [cited 2012 dec 31]. Guia de Doenças. Available from:

http://www.sbinfecto.org.br/publicoleigo/default.asp?siteAcao=mo straPagina\&paginald=9.

19. Innocente M, Oliveira LA, Gehrke C. Surto de ascaridíase intradomiciliar em região central urbana, Jacareí, SP, Brasil, junho de 2008. BEPA [Internet]. 2009 [cited 2012 dec 31];6(62):12-6. Available from:

ftp://ftp.cve.saude.sp.gov.br/doc tec/outros/bepa62 ascaridiasis.p df.

20. Secretaria Municipal de Saúde, Prefeitura Municipal de Ribeirão Preto. Plano Municipal de Saúde. Período 2010 - 2013 [Internet]. Ribeirão Preto: Prefeitura Municipal de Ribeirão Preto; 2009 [cited 2012 dec 31]. Available from:

http://www.ribeiraopreto.sp.gov.br/ssaude/vigilancia/planeja/pmsrp-2010-2013.pdf.

Artigo recebido em 29/09/2011. Aprovado para publicação em 02/07/2012. Artigo publicado em 31/12/2012. 